\title{
Design, Ergonomia e Impressão 3D: um exercício prático de desenvolvimento de projeto para protetores de tomada.
}

\section{Design, Ergonomics and 3D Printing: a practical exercise in project development for outlets plugs covers.}

\author{
SILVA, Nayana Gatinho \\ Universidade Federal do Maranhão, Graduanda em Design \\ nayanagsilva@gmail.com \\ SOUSA, Ferdinan \\ Universidade Federal do Maranhão, Graduando em Design \\ ferdinansousa.16@gmail.com
}

CAMPOS, Lívia Flavia De Albuquerque

Universidade Federal do Maranhão, Doutora em Design

liviaflavia@gmail.com

DEMAISON, André

Universidade Estadual Paulista, Doutorando em Design

demaison@gmail.com

\section{RESUMO}

O estudo refere-se ao desenvolvimento de um projeto para protetores de tomada, levando em consideração critérios ergonômicos e de usabilidade. O estudo foi desenvolvido em duas disciplinas do curso de graduação em Design (Projeto de Produto 1 e Ergonomia e Projeto de Produto), ocorrendo de maneira integrada a fim de corroborar conteúdos e as práticas do design na solução de um problema. Nesse caso, o problema abordado incluiu o risco de acidentes domésticos, principalmente envolvendo crianças. $O$ objetivo do projeto foi elaborar um novo produto mais eficiente, seguro e confortável. Para tanto, utilizouse a metodologia de desenvolvimento de produto proposta por Lobach (2001), juntamente com ferramentas apresentadas por Baxter (2011) e Análise da Tarefa (MORAES; MONT'ALVÃO, 2000). Testes de validação como Teste de Erick (CAVALCANTI, 2002) e uma escala de satisfação (SUS) (BROOKE, 1986) foram aplicados após a impressão 3D do protótipo. O estudo resulta em uma proposta conceitual para novos protetores de tomada, que fora testado e avaliado por usuários, a partir do protótipo desenvolvido. Os critérios ergonômicos e de usabilidade neste projeto de produto norteou a escolha de alternativas, a fim de melhorar os aspectos funcionais e consequentemente a satisfação dos indivíduos.

Protetor de tomada, Design de Produto, Ergonomia, Impressão 3D 


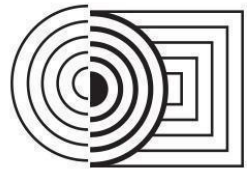

\section{$17^{\circ}$ ERGODESIGN \& USIHC 2019 \\ PUC-Rio, 11 a 13 de dezembro \\ Rio de Janeiro, RJ, Brasil}

$17^{\circ}$ Ergodesign - Congresso Internacional de Ergonomia e Usabilidade de Interfaces Humano Tecnológica: Produto, Informações Ambientes Construídos e Transporte

$17^{\circ}$ USIHC - Congresso Internacional de Ergonomia e Usabilidade de Interfaces Humano Computador

\begin{abstract}
The study refers to the design of outlets plugs covers, taking into account ergonomic and usability criteria. The study was developed in two subjects of the Design undergraduate course (Product Design 1 and Ergonomics and Product Design), developed in an integrated way to corroborate content and design practices in solving a problem. In this case, the problem addressed included the risk of domestic accidents, especially involving children. The aim of the project was to develop a new, more efficient, safe and comfortable product. For this, we used the product development methodology proposed by Lobach (2001), together with tools presented by Baxter (2011) and Task Analysis (MORAES; MONT'ALVÃO, 2000). Validation tests such as the Erick Test (CAVALCANTI, 2002) and a Satisfaction Scale (SUS) (BROOKE, 1986) were applied after 3D printing of the prototype. The study results in a conceptual proposal for new outlets plugs covers that has been tested and evaluated by users from the developed prototype. The ergonomic and usability criteria in this product project guided the choice of alternatives in order to improve functional aspects and, consequently, the satisfaction of individuals.
\end{abstract}

Outlets plugs covers, Design Product, Ergonomics, 3D Printing

\title{
1. INTRODUÇÃO
}

Com o advento da eletricidade, os eletrodomésticos passaram a fazer parte da vida das pessoas e, consequentemente, as tomadas elétricas também. Com a presença das tomadas, acidentes elétricos começaram a acontecer. Segundo a ABRACOPEL (Associação Brasileira de Conscientização para os Perigos da Eletricidade), no ano de 2018, os eventos com choque elétrico lideram o ranking de acidentes de origem elétrica no país, com 836 registros de casos fatais e não fatais. Entre as vítimas fatais de choques elétricos encontram-se as crianças de 0 a 10 anos as quais somaram 34 vítimas (5\%), sendo 20 delas de 0 a 5 anos (3\%).

Segundo Malacarne (2016), a curiosidade das crianças pode levá-las a algumas situações perigosas principalmente perto de objetos relacionados à eletricidade como fios, cabos e tomadas.

Os protetores para tomadas residenciais surgiram a partir da necessidade de impedir o contato acidental, principalmente de crianças, com a corrente elétrica. Considerando o crescimento na indústria de eletrodomésticos, nota-se que os protetores acompanham essa evolução. Percebese que o seu desenho segue os desenhos das tomadas, redondas, quadradas e retangulares, no caso das tomadas com interruptor, além dos pinos chatos e os de dois pinos redondos que simulam a forma dos plugues. Mesmo com essa evolução no ambiente doméstico devido aos vários modelos de protetores já disponibilizados no mercado, com o incentivo na utilização desses novos produtos, com o investimento na publicidade para alavancar as vendas e com o aumento de informações alertando pais e responsáveis sobre o uso doméstico de protetores de tomada, nota-se que acidentes ainda ocorrem. Dados da ABRACOPEL apresentam que, em 2018, os ambientes residenciais (somatória de unifamiliar+multifamiliar+sítios e fazendas) registraram 209 mortes, superando os acidentes que envolvem as redes aéreas de distribuição (172).

Assim, o objetivo do presente estudo é desenvolver um novo protetor de tomada, com foco na eficiência, conforto e segurança dos usuários. 


\section{RISCO E PERIGO DO CHOQUE ELÉTRICO EM AMBIENTE DOMÉSTICO}

Segundo Sanders e McCormick (1993, p. 675), "risco é a probabilidade ou chance de lesão ou morte". Já o perigo consiste em "[...] uma condição ou um conjunto de circunstâncias que têm o potencial de causar ou contribuir para uma lesão ou morte".

A Norma Regulamentadora № 10 (ABNT, 2004, p. 9) define perigo como "situação ou condição de risco com probabilidade de causar lesão física ou danos à saúde das pessoas por ausência de medidas de controle". E risco, a "capacidade de uma grandeza com potencial para causar lesões ou danos à saúde das pessoas".

Assim, no ambiente doméstico o risco de dano à saúde em virtude de acidentes envolvendo eletricidade é uma condição real e que merece atenção, principalmente quando há a presença de crianças na fase pré-escolar. Segundo Bezerra et. al (2014), nesta fase as causas externas são as mais responsáveis pelas lesões e óbitos que acometem crianças no Brasil e no mundo. Isto se deve ao conjunto de características que as tornam mais vulneráveis aos acidentes, como a imaturidade física, mental e comportamental. As crianças ficam mais propensas aos acidentes domésticos, dentre eles os choques elétricos, os quais são uma perturbação de natureza e efeitos diversos que se manifestam no organismo humano quando este é percorrido por uma corrente elétrica (KINDERMANN, 2000).

Segundo Malacarne (2016), dentro de casa, os maiores perigos são as tomadas sem proteção, fios desencapados e benjamins ("Ts"). Além de outras medidas, o uso de protetores de tomadas é recomendado por especialistas.

\section{MÉTODOS E TÉCNICAS}

Segundo Bomfim (1995), a metodologia é o estudo dos métodos, técnicas e ferramentas e de suas aplicações à definição, organização e solução de problemas teóricos e práticos.

Para o presente estudo, fez-se uso da metodologia projetual de Bernd Löbach (2000). Em sua proposta, o autor aponta que o processo de design é tanto um processo criativo como de solução de problemas e referência a lógica de avanços e retrocessos ao longo do processo de design, dividindo seu método em quatro fases: fase de preparação; fase de geração; fase de avaliação e fase de realização. Essas etapas nortearam todo o processo de desenvolvimento deste projeto.

A ergonomia também usa métodos e técnicas para observar o trabalho humano. Para realizar qualquer tarefa, o ambiente físico precisa estar adequado e em condições para receber o produto, evitando, assim resultados despropositados. Para o desenvolvimento de produtos, há uma vasta quantidade de métodos e técnicas que visam resolver os problemas e questões que envolvem o entorno material dos produtos existentes.

Com base na metodologia de Lobach, pode-se estruturar o projeto da seguinte forma:

Fase de preparação - Na referida fase, inicia-se o processo de solução do produto e o processo de design para desenvolvimento do produto. Segundo Lobach (2000), para primeira 
fase do processo de design é essencial a coleta máxima de informações possíveis para que se possa prepará-las para a fase posterior de avaliação. Aqui foram aplicadas as técnicas utilizadas para o desenvolvimento do projeto de produto (LOBACH, 2000) como a Análise da Necessidade, Análise Comparativa do Produto, Análise de Público Alvo, Análise do Mercado, além de técnicas da ergonomia como a Sistematização Homem-Tarefa-Máquina, Fluxograma da Tarefa, para a realização da apreciação ergonômica (MORAES E MONT'ALVÃO, 2000); para os testes de verificação utilizou-se os Testes de Usabilidade e Teste de Erick (CAVALCANTI, 2002), e por fim, para Análise de Satisfação aplicou-se o questionário SUS System Usability Scale (BROOKE, 1986).

Fase de Geração - Após a fase de preparação, onde se analisa o problema com seu entorno, ocorre a segunda fase, onde são geradas as alternativas para o mesmo (LOBACH, 2000). O autor afirma que nesta fase de produção de ideias, para que se possa gerar o maior número de alternativas possíveis, a mente precisa trabalhar livremente, sem restrições. Partindo desse princípio, fez-se uso das técnicas de Moodboard (MCDONAGH E DENTON, 2005), Mapa Mental (BUZAN, 2005), Brainstorming (VIANNA et al., 2012) e Brainwriting (MICHINOV, 2012), a fim de estimular a criatividade na geração de ideias.

Fase de Avaliação - A partir das alternativas apresentadas, pode-se encontrar qual a solução mais plausível diante dos critérios elaborados previamente (LOBACH, 2000). Para isso, foi gerado um produto conceito e desenvolvido um mockup, a fim de definir as dimensões do produto, levando em consideração os princípios da antropometria (PASCHOARELLI, 2000) e da biomecânica (IIDA 2005).

Fase de realização - Esta etapa é a materialização da alternativa escolhida. Lobach (2000) diz que a melhor alternativa apresentada na forma de um produto industrial, se converte então em um protótipo. Para tanto, foi elaborado o desenho técnico e modelagem digital do produto, e por fim a prototipação a partir da impressão 3D.

Validação - Esta etapa foi incluída, a fim de corroborar os atributos referente a funções e satisfação do usuário, onde foram aplicados novamente os testes de Usabilidade, Teste de Erick e o questionário SUS, com o protótipo do novo produto desenvolvido.

\subsection{Fase de Preparação}

\subsubsection{Análise da Necessidade}

Dados recentes apontam que o número de acidentes elétricos ainda ocorre dentro do ambiente doméstico, mesmo com a normatização, a evolução das tomadas e os meios criados como forma de prevenção aos riscos de choques elétricos, portanto o produto ainda se mostra de extrema importância para proteger as crianças. Segundo levantamento da ABRACOPEL em 2018 entre as vítimas fatais de choques elétricos as crianças de 0 a 10 anos somaram 34 vítimas (5\%), sendo 20 delas de 0 a 5 anos (3\%). 


\subsubsection{Análise Comparativa do Produto}

Realizou-se uma pesquisa em lojas físicas e online para analisar os protetores de tomada já disponibilizados no mercado, com foco nos modelos utilizados para o novo padrão de tomadas, o modelo de três pinos que entrou em vigência no cenário brasileiro a partir de 2012.

Foram encontradas 4 opções relevantes de acordo com as características definidas para análise sendo elas modelos adequados para o novo padrão de tomada e produzidos a partir do polipropileno (Tabela 1).

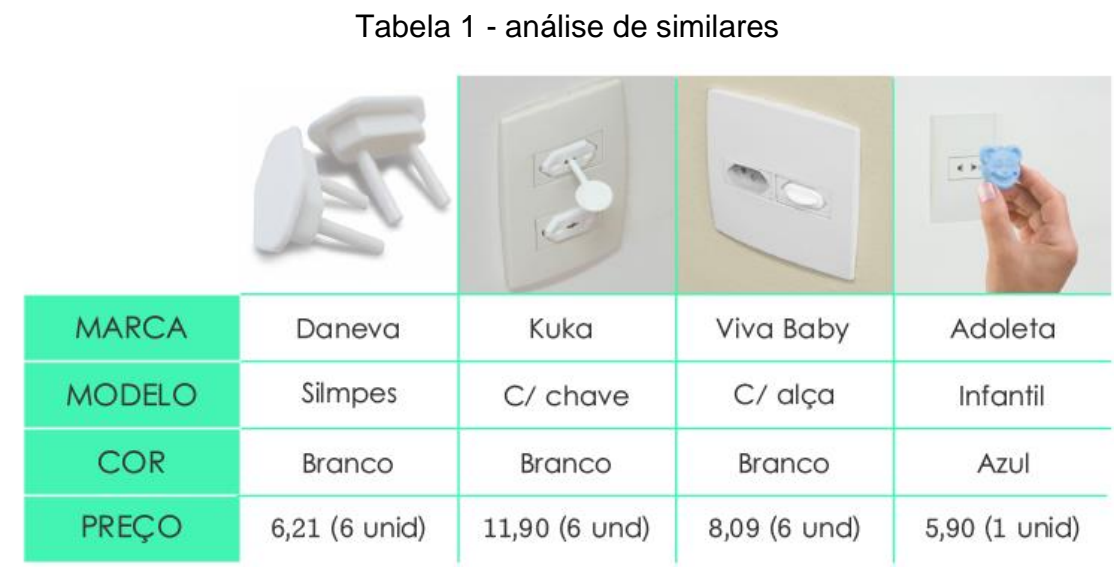

Fonte: Os autores

\subsubsection{Público alvo}

Para a definição do público-alvo, fez-se a aplicação de um questionário online e entrevistas presenciais, que totalizaram um número de 40 entrevistados entre 18 a 56 anos, a fim de conhecer os usuários do produto.

Através desse levantamento, concluiu-se que existem mais de um público direto, são eles: pais/ mães e crianças na faixa etária de 1 a 4 anos; e um público indireto, familiares e babás. A procura e utilização dos produtos é dada, na maioria das vezes, por um público feminino, o que correspondeu a $71 \%$ dos entrevistados. A maioria dos usuários (87\%) que utilizam os protetores, residem com criança(s) e afirmam só usarem até os primeiros 4 anos de idade. $\mathrm{E}$ quando não há criança pequena no domicílio, ocorre o desuso do acessório.

\subsubsection{Análise do Mercado}

Também com base nos questionários online e nas entrevistas, constatou-se que o modelo mais utilizado para proteger as tomadas é o modelo simples (Figura 1), de superfície plana e sem presença de componentes como chaves (46,2\%). O motivo varia entre ser o modelo mais barato e o mais encontrado no mercado. 
$17^{\circ}$ ERGODESIGN \& USIHC 2019

PUC-Rio, 11 a 13 de dezembro

Rio de Janeiro, RJ, Brasil $17^{\circ}$ Ergodesign - Congresso Internacional de Ergonomia e Usabilidade de Interfaces Humano Tecnológica: Produto, Informações Ambientes Construídos e Transporte

$17^{\circ}$ USIHC - Congresso Internacional de Ergonomia e Usabilidade

de Interfaces Humano Computador

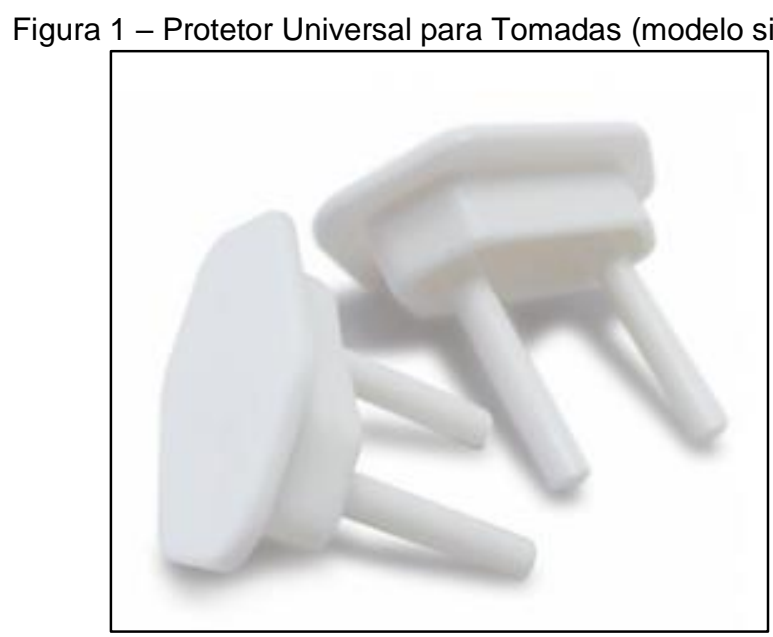

Fonte: Magazineluiza.com.br

Houveram entrevistados que afirmaram o desuso (41\%), onde os principais motivos seriam a ausência de criança(s) pequena(s) na residência ou por só possuírem tomadas altas em casa. Alguns entrevistados relataram, que faziam o uso de produtos alternativos para a proteção das tomadas, como o uso de fita isolante, por exemplo. Outros afirmaram que vigiavam a criança de modo que não viam necessidade de uso do produto. Por fim, havia aqueles que vivenciaram algum tipo de frustração em relação ao uso do produto, como a dificuldade de um adulto no momento de remoção do acessório, ou a facilidade da criança para remover o protetor da tomada. A maior parte dos entrevistados (59\%) afirmaram não ter dificuldade de encontrar protetores de tomadas no mercado. A maioria (77\%) não considera um produto caro.

\subsubsection{Sistema-Homem-Tarefa-Máquina (SHTM)}

Nessa fase inicial, de análise do problema, realizou-se uma apreciação ergonômica, com a Sistematização Homem-Tarefa-Máquina, proposta por Moraes e Mont'Alvão (2000). Essa etapa consiste na apresentação ilustrada do problema através da elaboração de quadros, tabelas e fluxogramas. Nessa sistematização cabe enfatizar a interação entre homens e máquinas. Entende-se por máquina tudo aquilo que compreende qualquer mecanismo com o qual o usuário executa uma atividade com um dado propósito. (BRANDÃO, 2012).

Na sistematização, o sistema alvo foi o uso do protetor de tomada e a meta do sistema foi proteger o usuário contra choques elétricos. Observa-se o esquema na Figura 2 e sua hierarquia na Figura 3. 
$17^{\circ}$ ERGODESIGN \& USIHC 2019

PUC-Rio, 11 a 13 de dezembro

Rio de Janeiro, RJ, Brasil $17^{\circ}$ Ergodesign - Congresso Internacional de Ergonomia e Usabilidade de Interfaces Humano Tecnológica: Produto, Informações Ambientes Construídos e Transporte

$17^{\circ}$ USIHC - Congresso Internacional de Ergonomia e Usabilidade

de Interfaces Humano Computador

Figura 2 - Sistema Homem Tarefa Máquina do uso de protetores de tomada

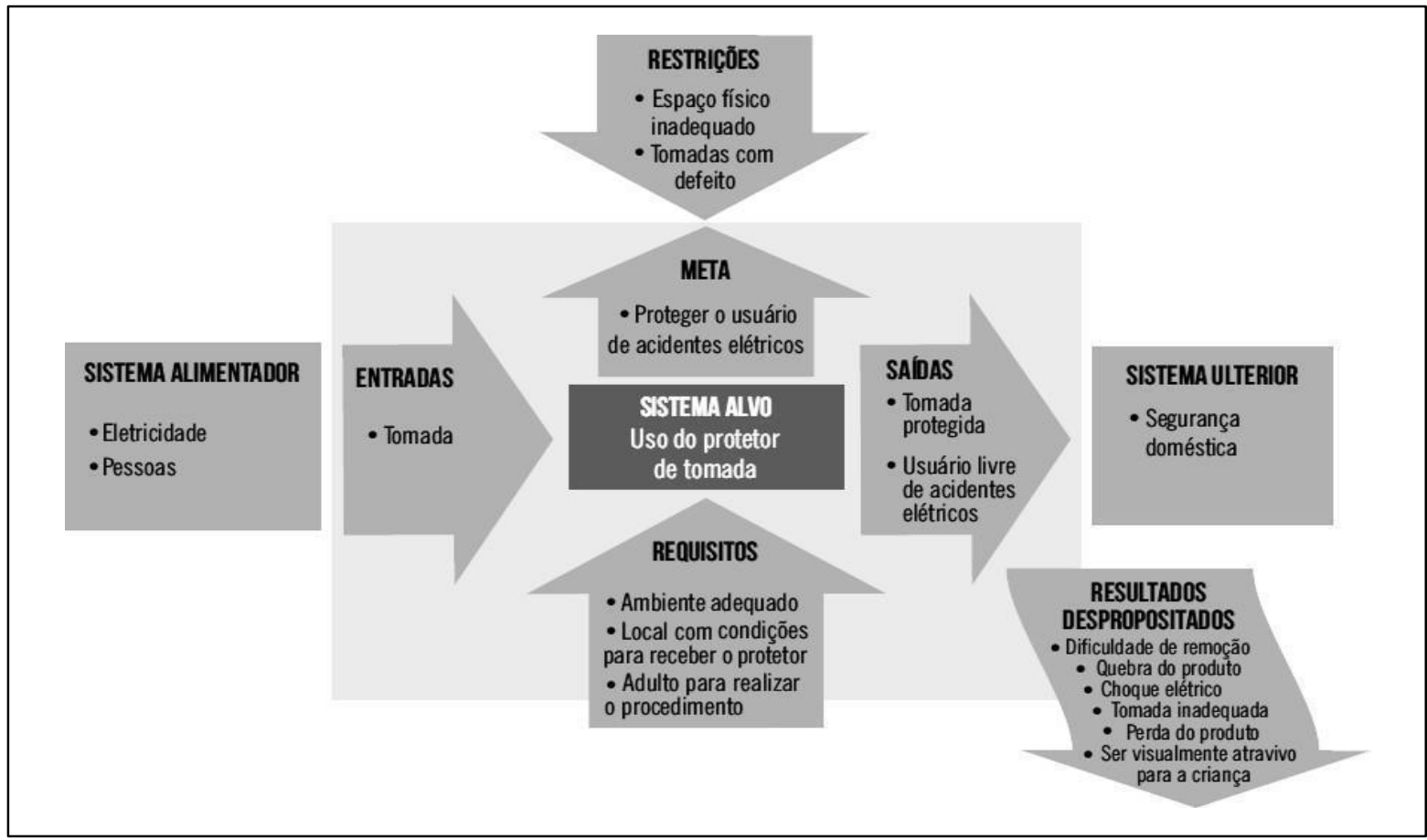

Fonte: Os autores

Figura 3 - Hierarquia do Sistema Homem Tarefa Máquina

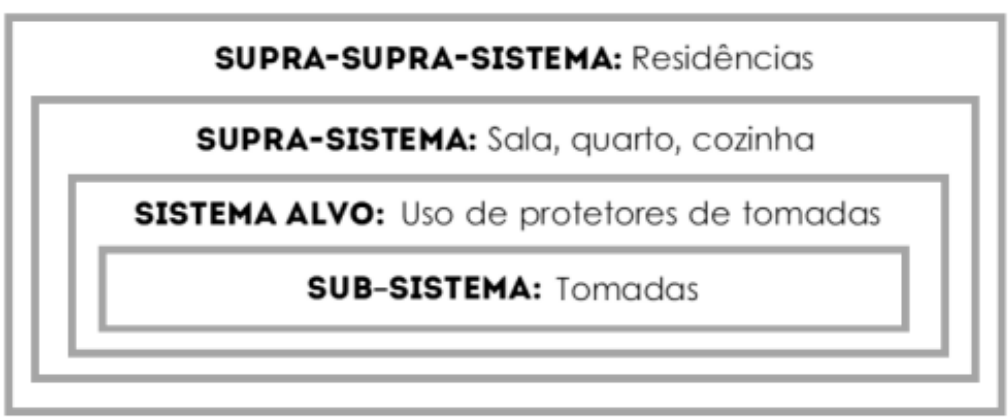

Fonte: Os autores

\subsubsection{Fluxograma da tarefa}

Realizou-se uma simulação de uso, registrada por meio de fotos, de todas as etapas de utilização do protetor de tomada realizada, desde a retirada do plugue até a realocação do mesmo. Visou-se compreender todos os componentes da tarefa e identificar as possíveis falhas no sistema. A partir da simulação da utilização do protetor de tomada, criou-se um fluxograma detalhado da tarefa. 


\section{$17^{\circ}$ ERGODESIGN \& USIHC 2019}

PUC-Rio, 11 a 13 de dezembro

Rio de Janeiro, RJ, Brasil $17^{\circ}$ Ergodesign - Congresso Internacional de Ergonomia e Usabilidade de Interfaces Humano Tecnológica: Produto, Informações Ambientes Construídos e Transporte

$17^{\circ}$ USIHC - Congresso Internacional de Ergonomia e Usabilidade de Interfaces Humano Computador

Figura 4 - Simulação da utilização do protetor de tomada

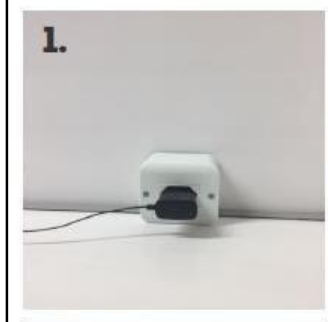

5.

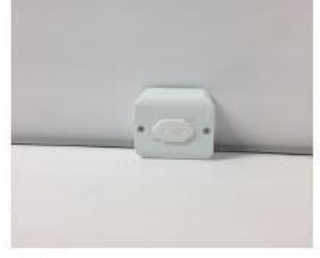

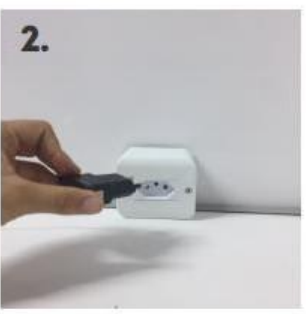

6.

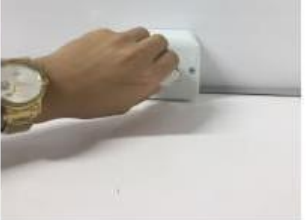

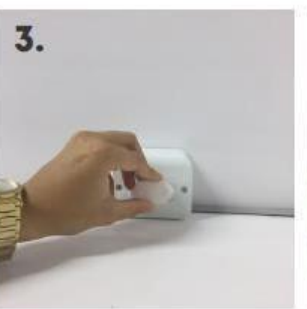

7.

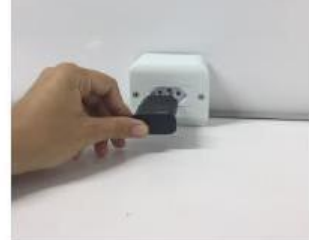

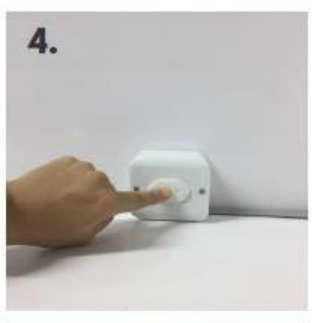

8.

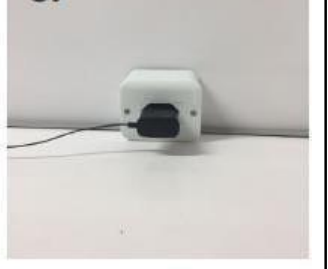

Fonte: Os autores

Figura 5 - Fluxograma detalhado da tarefa do uso do protetor de tomada simples

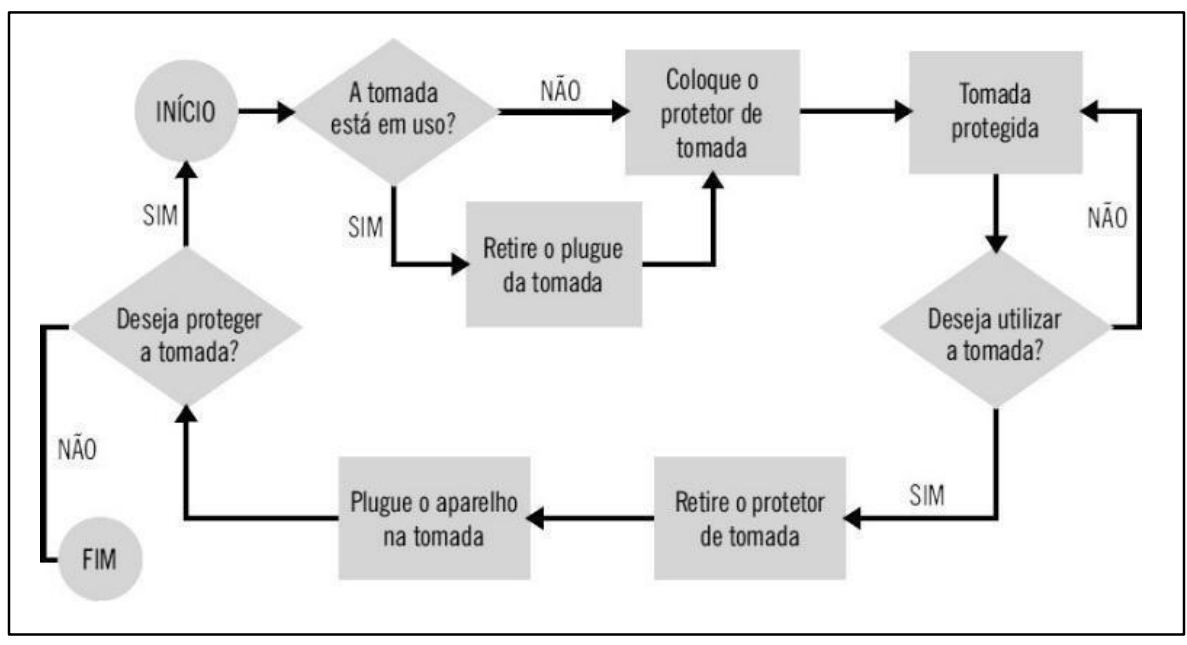

Fonte: Os autores

\subsubsection{Teste de Usabilidade e Teste de Erick}

Com intuito de verificar outras possíveis formas de utilização e validar o fluxo dos usuários ao utilizarem o protetor de tomada simples, decidiu-se aplicar um teste de usabilidade, onde houve a simulou-se a real utilização, a partir de um carregador de celular e de um protetor de tomada.

Decidiu-se aplicar em paralelo aos testes de usabilidade outro método, denominado Teste de Erick (Cavalcanti, 2002. O teste consistiu em identificar a principal região de contato, a partir da aplicação de uma camada de tinta sob a superfície do produto e posterior impressão da mancha gerada, em uma folha de papel.

Figura 6 - Fluxograma detalhado da tarefa do uso do protetor de tomada simples 


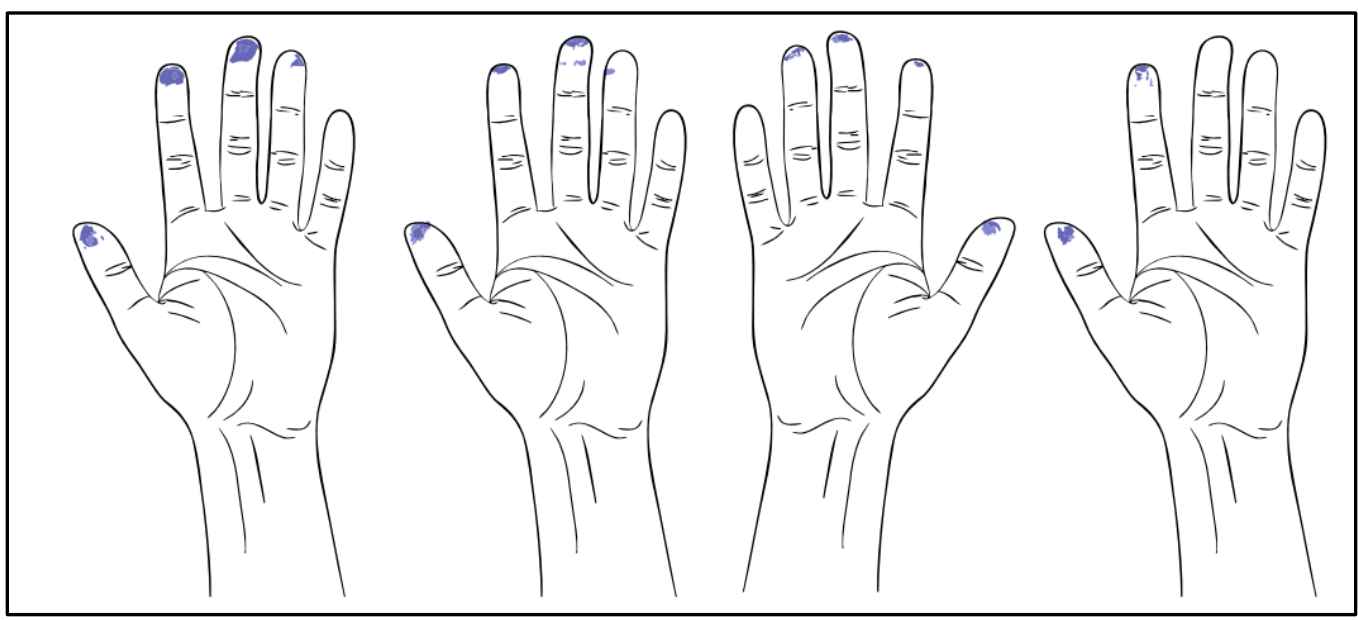

Fonte: Os autores

O teste foi aplicado com 5 mulheres, sendo elas mães e pessoas que fazem o uso de protetores em casa, devido a presença de crianças. A partir dele foi possível confirmar o fluxo da tarefa executada, sem muitas diferenças pelos usuários, e também identificar as áreas que o usuário utiliza para fazer o manuseio do protetor de tomada simples.

Observou-se que os dedos utilizados para remover o produto são: o polegar, o indicador, o médio e o anelar, mas alguns usuários utilizam apenas o polegar e o indicador. Além disso, a parte dos dedos que faz contato com a área de pega do produto são apenas as falanges. Notase que a área de pega é pequena. Isso se dá pela superfície estreita que o produto apresenta como área de contato para o usuário.

\subsubsection{Análise de satisfação - SUS}

Após o anterior optou-se pela aplicação do SUS, método de averiguação do nível de usabilidade em relação ao uso de um determinado produto ou sistema. Proposto por Brooke (1986), o método pretende avaliar aspectos como efetividade, eficiência e satisfação, consistindo em dez perguntas, por padrão, sendo elas aqui apenas adaptadas ao contexto. $O$ questionário contou com as seguintes perguntas:

1. Eu acho que gostaria de usar esse produto de tomada com frequência.

2. Eu acho o produto desnecessariamente complexo.

3. Eu achei o produto fácil de usar.

4. Eu acho que precisaria de ajuda de uma pessoa com conhecimentos técnicos para usar o produto.

5. Eu acho que as várias funções do produto estão muito bem integradas.

6. Eu acho que o produto apresenta muita inconsistência. 
7. Eu imagino que as pessoas aprenderão como usar esse produto rapidamente.

8. Eu achei o produto atrapalhado de usar.

9. Eu me senti confiante ao usar o produto.

10. Eu precisei aprender várias coisas novas antes de conseguir usar o produto.

As respostas são obtidas por meio de uma escala entre 1 e 5 , onde 1 equivale a "discordo completamente" e 5 equivale a "concordo completamente. As respostas são mensuradas a partir do seguinte cálculo: para as perguntas ímpares subtrai-se 1 da resposta dada pelo usuário e para as perguntas pares subtrai-se a resposta do usuário por 5 . Em seguida, faz-se a soma dos valores obtidos e multiplica-se por 2.5. A pontuação final pode variar entre 0 e 100 pontos, sendo a média aceitável de 68 pontos, ou seja, pontuações menores que estas apontam para sérios problemas de usabilidade, já as maiores apontam para bons aspectos de satisfação.

O teste também fora realizado pelas cinco mães que participaram dos testes anteriores. A média dos resultados obtidos nos questionários foi 67.5 , o que implica dizer que o produto atual possui problemas de usabilidade.

\subsubsection{Normas}

Cada norma técnica geralmente trata de um assunto específico. Portanto, quando é definido um padrão, como o dos plugues e tomadas, ele é geralmente formado por um conjunto delas, cada qual atendendo um aspecto, como proteção, isolação, durabilidade, adaptações, dimensões físicas, materiais utilizados, etc.

A norma utilizada como referência foi NBR 14136, que foi proposta em 1989 e aprovada em 2000, entrando em vigor no Brasil em 2012. A norma foi usada para entender o novo padrão para assim ser possível construir o produto de acordo com o objetivo de atender o público brasileiro.

\subsection{Fase de Geração}

Aqui são propostas alternativas de solução utilizando conceitos de design, esboço de ideias e modelos. Para esse processo se fez o uso de técnicas de criatividade desenvolvidas para implementar a geração de ideias.

As técnicas de criatividade são atividades desenvolvidas com um conjunto de pessoas para a definição de um problema, avaliação, seleção, implementação de ideias e geração de ideias criativas e inovadoras.

\subsubsection{Moodboard}

Segundo McDonagh e Denton (2005), os moodboards geralmente são configurados por uma compilação de elementos visuais com o intuito de estimular a comunicação e o desenvolvimento no processo de design. O moodboard (Figura 7) do público alvo, também conhecido como Painel Semântico, foi construído a partir do perfil da persona gerada. Nele observa-se elementos da rotina de uma mãe com seu filho, a energia da personalidade das 
crianças, unido à um estilo de vida saudável, ligado à natureza, representados por uma paleta de cores vibrantes e bastante saturadas.

Figura 7 - Moodboard

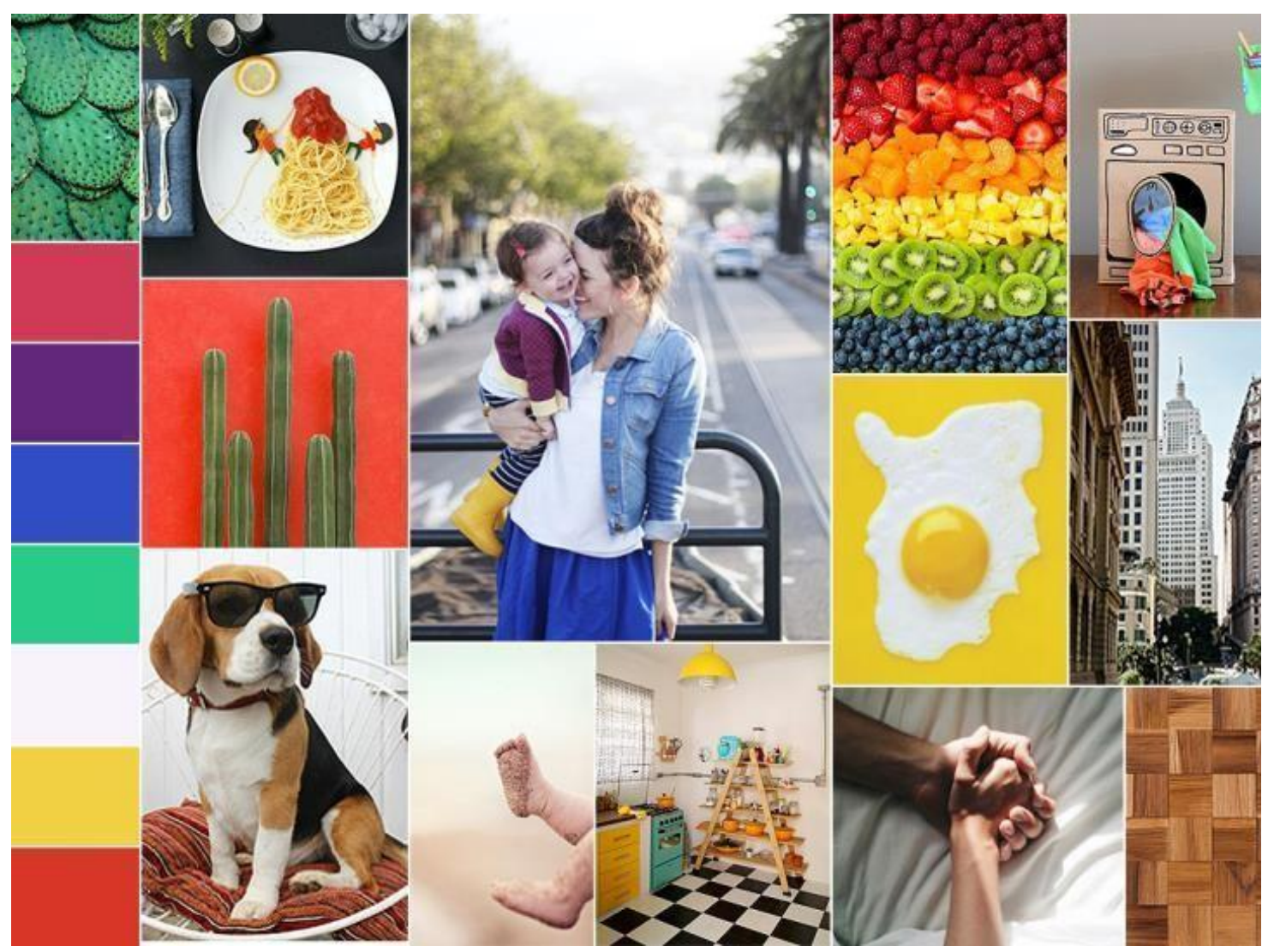

Fonte: Os autores

\subsubsection{Mapa Mental}

Os mapas são estruturas radiais, o que significa que as informações neles contidas são dispostas em raios. Buzan (2005) propõe que o mapa mental use cores, tenha uma estrutura natural que parte do centro, utilize linhas curvas, símbolos, palavras, imagens, opere em harmonia com o cérebro e possua ramificações orgânicas que estimulem os olhos. A Figura 8 demonstra a aplicação desse método, como estímulo para a geração de ideias do produto em estudo. 
$17^{\circ}$ ERGODESIGN \& USIHC 2019

PUC-Rio, 11 a 13 de dezembro

Rio de Janeiro, RJ, Brasil $17^{\circ}$ Ergodesign - Congresso Internacional de Ergonomia e Usabilidade de Interfaces Humano Tecnológica: Produto, Informações Ambientes Construídos e Transporte

$17^{\circ}$ USIHC - Congresso Internacional de Ergonomia e Usabilidade de Interfaces Humano Computador

Figura 8 - Mapa mental elaborado para solucionar problemas do produto

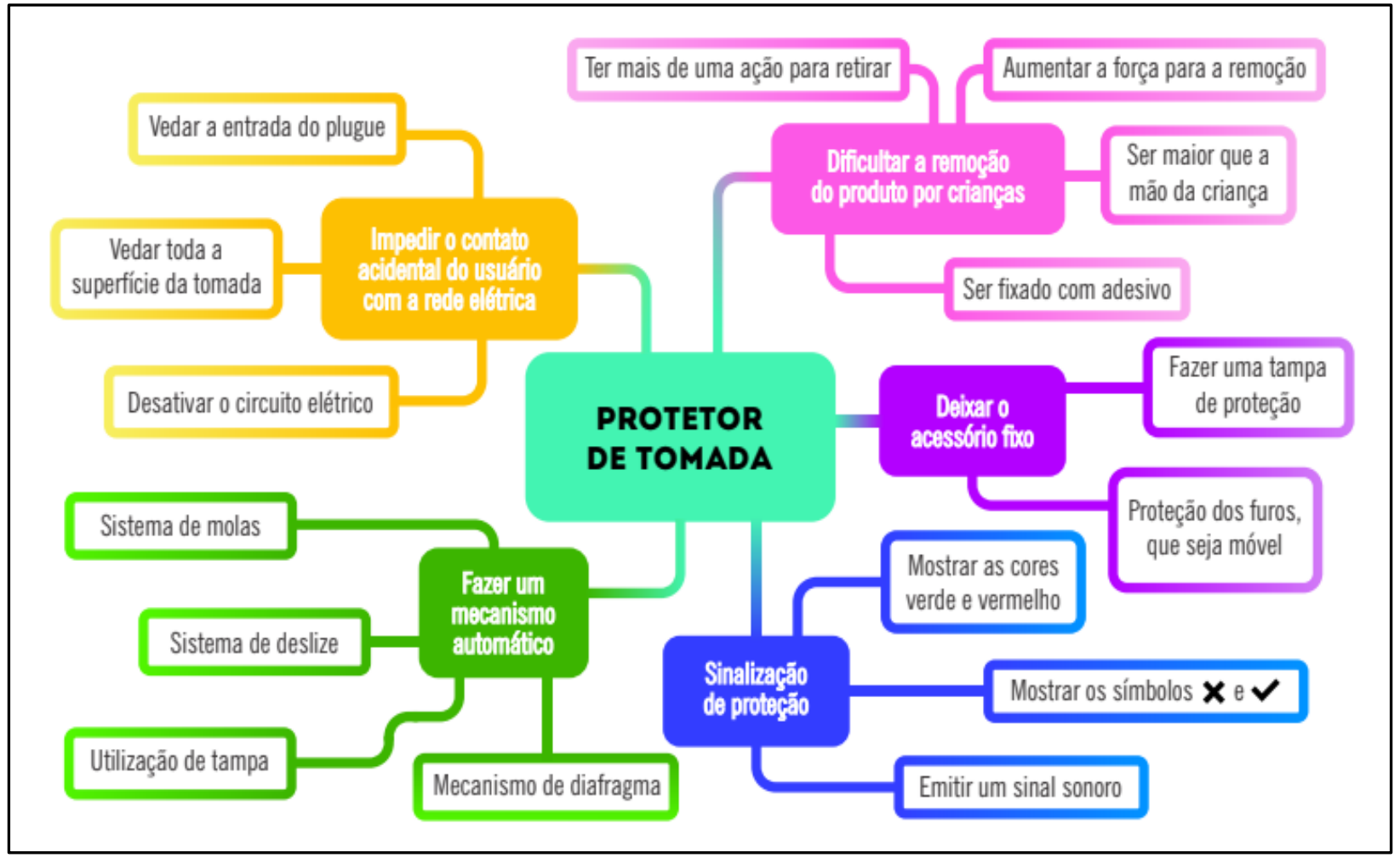

Fonte: Os autores

\subsubsection{Brainstorming e Brainwriting}

Segundo Vianna et al. (2012), a técnica de brainstorming é utilizada para estimular o surgimento do maior número possível de ideias em um espaço pequeno de tempo. $O$ brainstorming foi realizado mais de uma vez, com intervalos propositais para pensar em soluções alternativas com base em coisas do cotidiano. A partir dessas, outro brainstorming foi elaborado a fim de tornar visível as propostas de soluções geradas e estimular novas ideias a partir delas. Com o objetivo de gerar o máximo de ideias, durante a realização das técnicas não se pensou em requisitos projetuais ou qualquer fator delimitante. Além disso, não foi permitido que houvesse nenhum tipo de crítica ou julgamento às ideias que surgiam, para assim fazer conexões entre todas as sugestões. Ao final foi feito um debate e seleção das ideias das alternativas apresentadas.

O brainwriting é uma técnica similar ao brainstorming, usada para fomentar a geração de ideias (MICHINOV, 2012). Porém, no brainwriting (Figura 9) os participantes não verbalizam suas ideias, mas são representadas em um papel. Ao final as ideias de cada um são apresentadas aos demais componentes do grupo para serem analisadas, discutidas e incrementadas. 
$17^{\circ}$ ERGODESIGN \& USIHC 2019

PUC-Rio, 11 a 13 de dezembro

Rio de Janeiro, RJ, Brasil $17^{\circ}$ Ergodesign - Congresso Internacional de Ergonomia e Usabilidade de Interfaces Humano Tecnológica: Produto, Informações Ambientes Construídos e Transporte

$17^{\circ}$ USIHC - Congresso Internacional de Ergonomia e Usabilidade

de Interfaces Humano Computador

Figura 9 - Rascunhos do processo de brainwriting

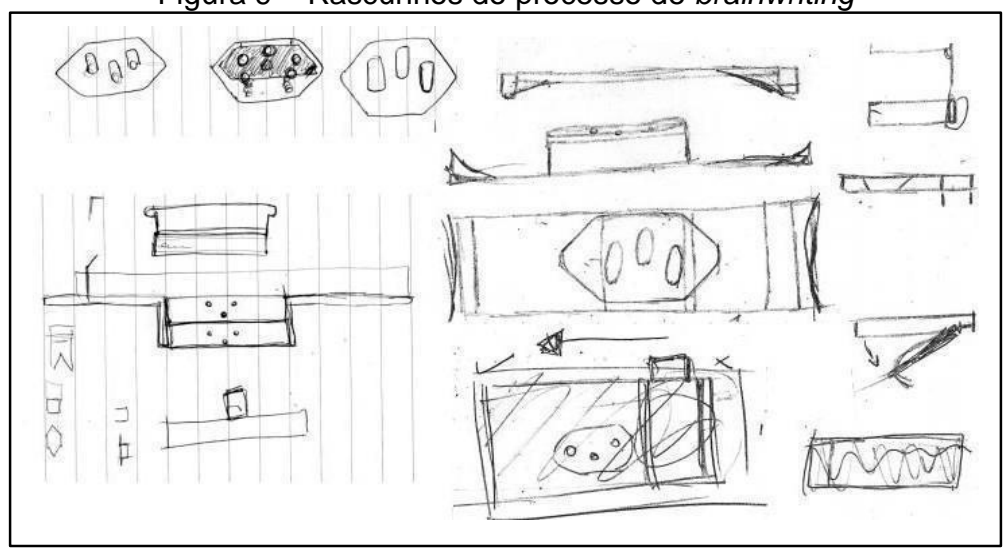

Fonte: Os autores

\subsection{Fase de Avaliação}

Nesta etapa, é feita a avaliação de alternativas de design e escolha da melhor solução. A partir dos dados coletados, pode-se chegar a um modelo conceito. Nesta fase, foi feito o mockup utilizando massa epóxi para dimensionar o modelo, principalmente as áreas de pega do produto.

\subsubsection{Produto Conceito}

A proposta é um produto que proporcione segurança ao usuário e que the gere uma melhor experiência. Sendo assim, o novo modelo (Figura 10) segue a premissa de que o usuário poderá utilizar a tomada sem a necessidade de remover o protetor. Dentre suas principais características estão uma área de pega maior e rugosa, garantindo mais firmeza para manusear o produto; um mecanismo semiautomático de vedação, composto por placas e molas (Figura 14), onde a tomada ficaria protegida e para o uso dela o usuário colocaria os pinos no orifício do acessório e com um movimento de deslize para baixo ocasionaria no acesso dos pinos à tomada; e uma superfície autocolante para fixá-lo melhor à tomada, evitando assim a remoção acidental por crianças.

Figura 10 - Produto conceito

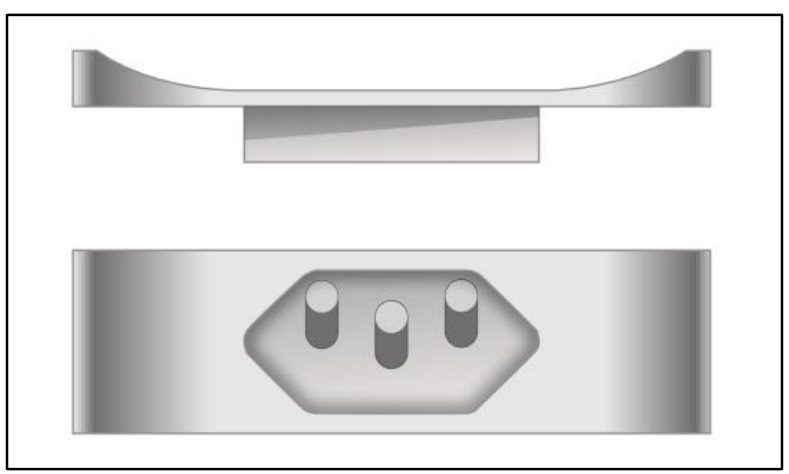

Fonte: Elaborado pelos autores, com base na pesquisa realizada 


\subsubsection{Mockup do produto}

Inicialmente foi produzido um mockup, utilizando massa epóxi, para testar as dimensões, principalmente as áreas de pega. Para a concepção, foram observadas as medidas antropométricas, coletados da tabela de Pheasant (1996) apresentada por Paschoarelli (2000), como a largura do polegar, largura do dedo indicador e abertura funcional máxima de homens e mulheres, considerando os percentis 5 e 95 de ambos (Tabela 2). Além disso, considerando os aspectos relacionados às posturas do punho e da mão.

Tabela 2 - Estimativa antropométrica das mãos relevantes ao projeto

\begin{tabular}{|l|c|c|c|c|}
\hline DADOS ANTROPOMÉtRICOS $(\mathrm{mm})$ & \multicolumn{2}{|c|}{ HOMEM } & \multicolumn{2}{c|}{ MULHER } \\
\hline VARIÁVEIS & P 05 & P 95 & P 05 & P 95 \\
\hline Largura do polegar & 20 & 26 & 17 & 21 \\
\hline Largura do dedo indicador & 19 & 23 & 16 & 20 \\
\hline Abertura funcional máxima & 122 & 162 & 109 & 145 \\
\hline
\end{tabular}

Fonte: Adaptada de Pheasant (1996)

A localização e o tamanho do objeto alteram a postura do punho e dos dedos, modificando a posição do usuário em relação ao objeto. No estudo da biomecânica observa-se que vários movimentos podem ser identificados para desempenhar atividades da vida diária. A preensão é aliada à aplicação de força muscular, permitindo a realização de tarefas (IIDA 2005). O tipo de pega identificado na tarefa é a Pega de Precisão ou Movimento de Pinça (IIDA, 2005), onde a mão envolve o equipamento, no caso o protetor, em um sistema de pinça entre o indicador e o polegar.

As dimensões utilizadas para a concepção da área de pega do mockup (Figura 11) foram a de $7 \times 23 \mathrm{~mm}$, devido a variante do dedo indicador de homens do percentil 95. O comprimento total do produto é de $80 \mathrm{~mm}$, tamanho que está dentro dos parâmetros de abertura funcional máxima dos percentis 5 e 95 de homens e mulheres. Além disso, é um tamanho que permite um encaixe ideal à superfície da tomada. As outras medidas seguiram os padrões da tomada, como os orifícios internos e angulação das bordas da parte interna, para permitir encaixe do acessório ao padrão brasileiro.

Figura 11 - Mockup do produto conceito

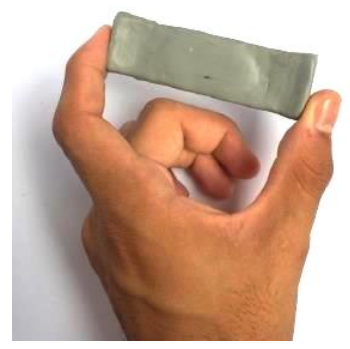

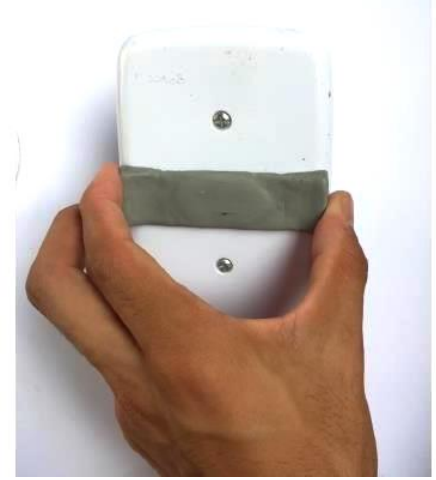

Fonte: Os autores
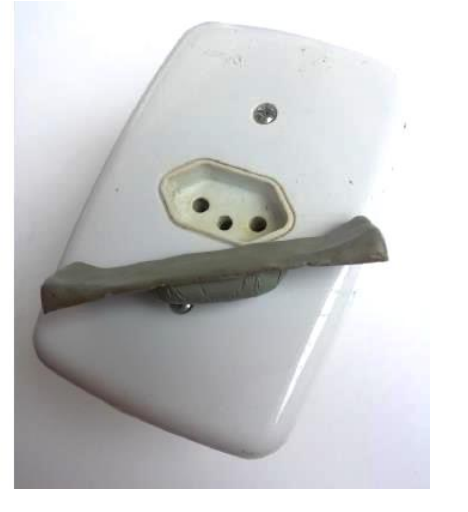
$17^{\circ}$ ERGODESIGN \& USIHC 2019

PUC-Rio, 11 a 13 de dezembro

Rio de Janeiro, RJ, Brasil $17^{\circ}$ Ergodesign - Congresso Internacional de Ergonomia e Usabilidade de Interfaces Humano Tecnológica: Produto, Informações Ambientes Construídos e Transporte

$17^{\circ}$ USIHC - Congresso Internacional de Ergonomia e Usabilidade de Interfaces Humano Computador

\subsection{Fase de Realização}

O último passo desse processo de design, conforme Lobach (2000), é a materialização da alternativa escolhida. Para tanto, foi desenvolvido o desenho técnico, modelagem e prototipação do produto conceito.

\subsubsection{Desenho Técnico e Modelagem 3D}

Com base no mockup e com o auxílio de softwares como AutoCAD e SketchUp, desenvolveu-se o desenho técnico (Figura 12) e em seguida, o modelo em 3D do projeto (Figura 13 e 14).

Figura 12 - Desenho técnico do produto conceito

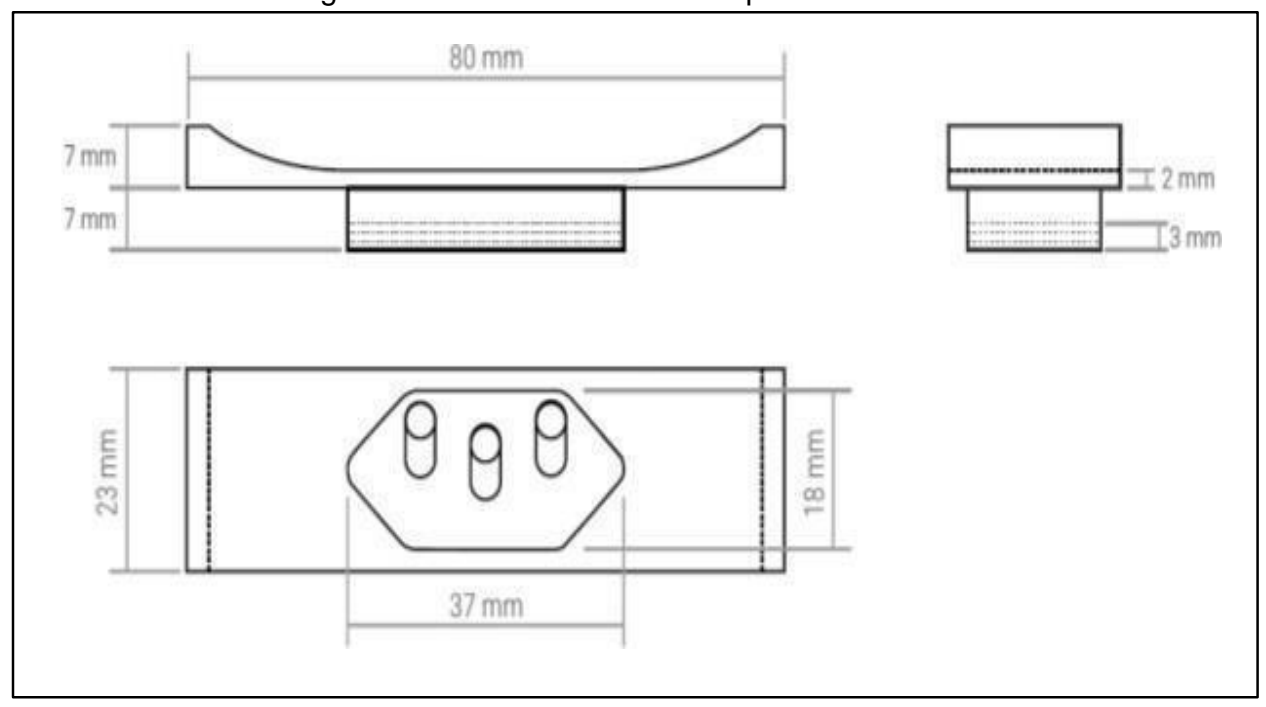

Fonte: Os autores

Figura 13 - Modelagem do produto conceito
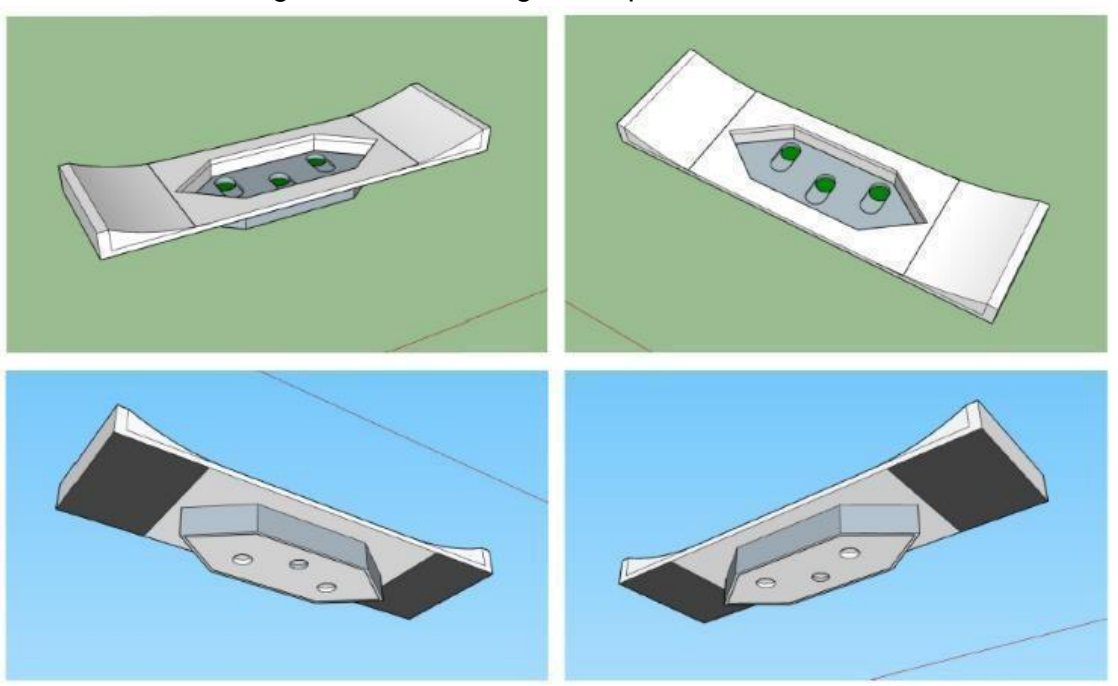

Fonte: Os autores 


\section{$17^{\circ}$ ERGODESIGN \& USIHC 2019}

PUC-Rio, 11 a 13 de dezembro

Rio de Janeiro, RJ, Brasil $17^{\circ}$ Ergodesign - Congresso Internacional de Ergonomia e Usabilidade de Interfaces Humano Tecnológica: Produto, Informações Ambientes Construídos e Transporte

$17^{\circ}$ USIHC - Congresso Internacional de Ergonomia e Usabilidade

de Interfaces Humano Computador

Figura 14 - Visão explodida do produto conceito

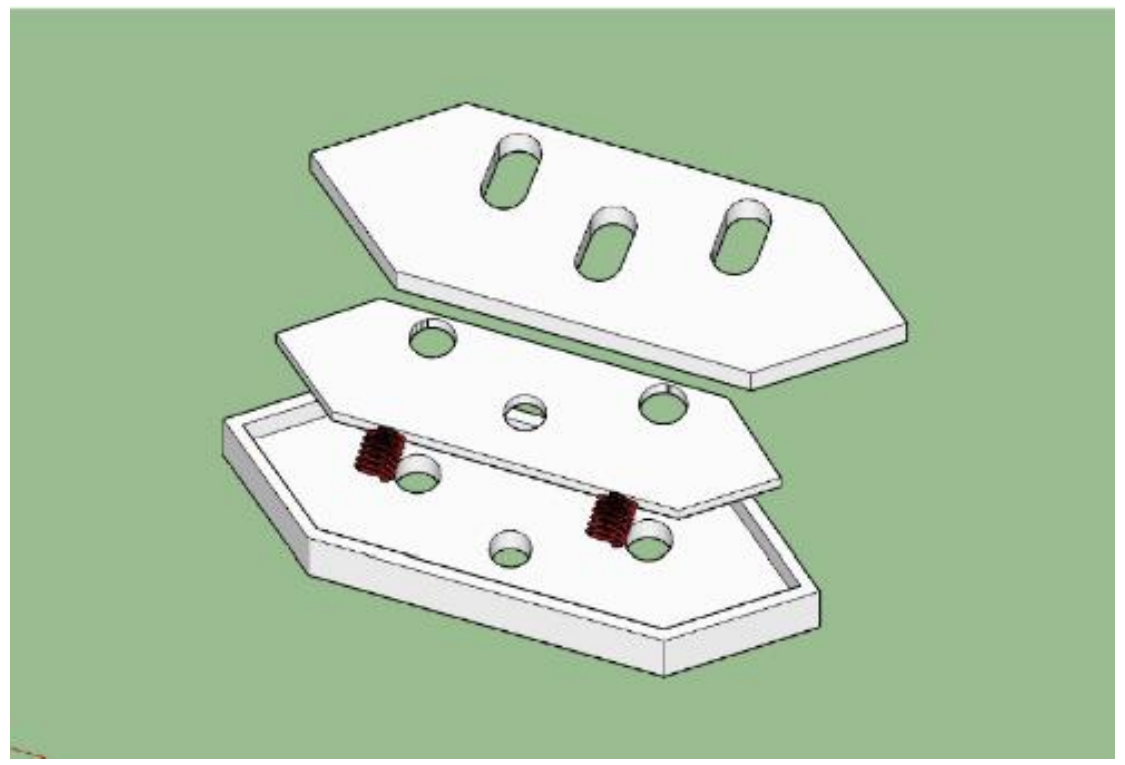

Fonte: Os autores

\subsubsection{Impressão 3D}

A partir do modelo 3D virtual desenvolvido foi possível desenvolver o protótipo utilizando a impressora Ultimaker (Figura 15) em um dos laboratórios de produto, dentro da universidade. Devido à algumas restrições da impressão 3D, optou-se por imprimir as partes do protótipo separadamente, conforme mostra a Figura 16, e uni-las posteriormente. As dimensões utilizadas foram as mesmas estabelecidas pelo projeto, em escala real e o material utilizado foi o polímero acrilonitrila butadieno estireno, conhecido como ABS. Esse material permite o uso do protótipo em ambiente real por não apresentar riscos em caso de contato com a rede elétrica.

Figura 15 - Impressora 3D Ultimaker

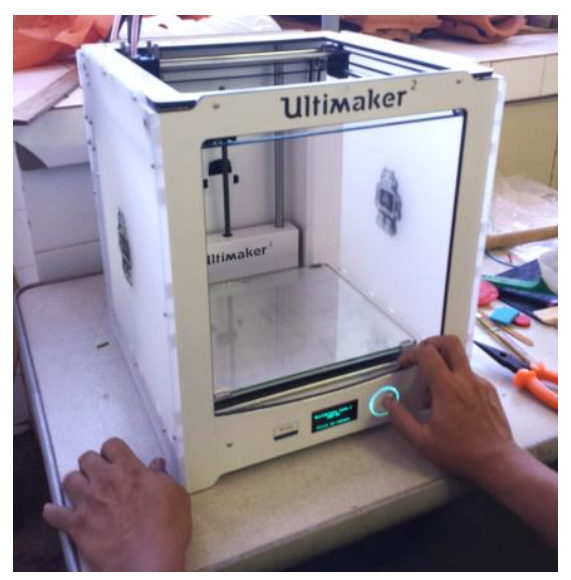

Fonte: Os autores 


\section{$17^{\circ}$ ERGODESIGN}

\section{\& USIHC 2019}

PUC-Rio, 11 a 13 de dezembro

Rio de Janeiro, RJ, Brasil $17^{\circ}$ Ergodesign - Congresso Internacional de Ergonomia e Usabilidade de Interfaces Humano Tecnológica: Produto, Informações Ambientes Construídos e Transporte

$17^{\circ}$ USIHC - Congresso Internacional de Ergonomia e Usabilidade

de Interfaces Humano Computador

Figura 16 - Partes do protótipo impressas

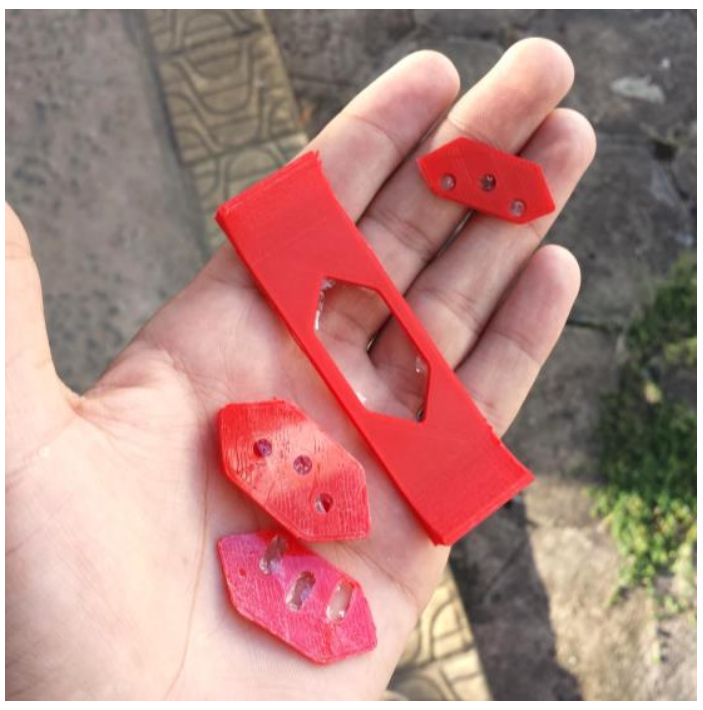

Fonte: Os autores

\subsection{Validação}

\subsubsection{Teste de Usabilidade e Fluxograma da Tarefa}

Para validar o protótipo (Figura 17), optou-se por realizar um novo teste de usabilidade. O teste de usabilidade foi realizado com 6 pessoas, sendo elas 2 homens e 4 mulheres, entre 19 e 33 anos de idade. Para esta fase, não foram consideradas apenas as mães, como no teste anterior, mas pessoas que fazem parte do público-alvo indireto, com diferentes faixas etárias. 0 teste foi realizado com o protótipo, gerado por meio da impressão 3D.

Figura 17 - Protótipo do produto conceito

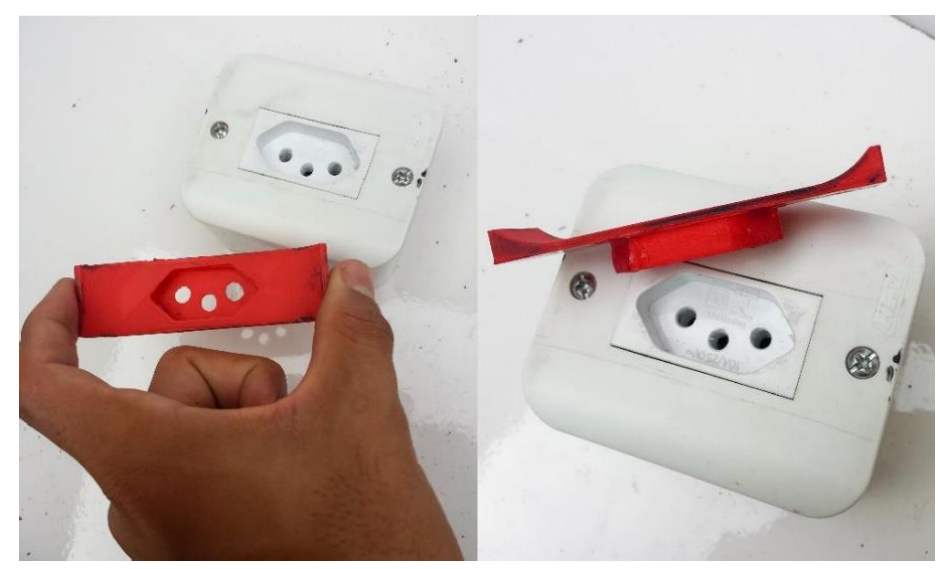

Fonte: Os autores

Após a explicação do conceito e funcionamento do mecanismo do produto, foi proposta aos avaliados a realização da tarefa que consiste em usar a tomada, protegê-la e fazer o uso dela 
novamente, enquanto o tempo era cronometrado. Para facilitar o entendimento dos usuários, foi apresentado o fluxograma da tarefa (Figura 18) para a execução do teste.

Figura 18 - Fluxograma detalhado da tarefa do produto conceito

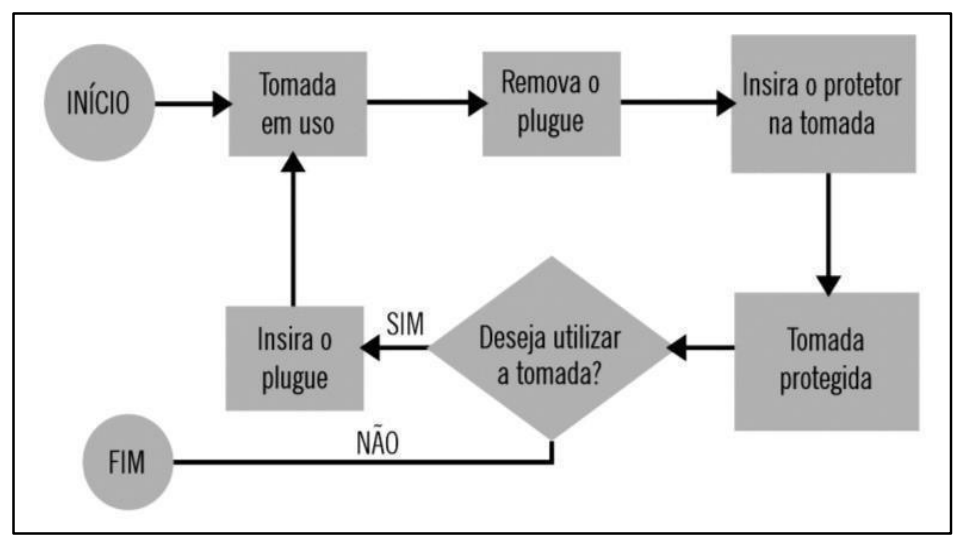

Fonte: Elaborado pelos autores

O tempo gasto pelos usuários com a simulação do uso com o produto novo variou entre 10 e 15 segundos. A área de pega do produto foi facilmente reconhecida pelos usuários e a maioria dos usuários utilizou apenas uma das mãos, em movimento de pinça, para remover o produto. Em alguns casos, a forte aderência da fita utilizada e os cantos retos do protótipo impresso foram os poucos fatores por dificultar a remoção.

\subsubsection{Validação de Satisfação - SUS}

Para mensurar a satisfação dos usuários em relação ao novo produto, aplicou-se novamente após os testes de usabilidade, o questionário do SUS.

Como resultado, obteve-se como menor média a pontuação de 77.5 , sendo todas as outras superiores ou igual a 92.5, chegando a atingir a pontuação máxima de 100 pontos. Todas as pontuações ultrapassaram a média de 68 pontos, ou seja, os dados não apontam para problemáticas na usabilidade do produto.

\subsubsection{Teste de Erick com o protótipo}

Após o questionário, para avaliação do protótipo, aplicou-se novamente o Teste de Erick para a verificação das dimensões propostas para a área de pega utilizadas para a remoção do produto. Como mostra a Figura 19, os dedos utilizados continuam sendo principalmente o polegar e o indicador e a área de contato aumentou significativamente, se comparada com o teste realizado com o protetor de tomadas simples (Figura 6). Este aumento da área de pega, garantiu aos usuários uma maior facilidade de remoção do produto, visto que as repetidas tentativas para remoção do produto diminuíram significantemente. 
$17^{\circ}$ ERGODESIGN \& USIHC 2019

PUC-Rio, 11 a 13 de dezembro

Rio de Janeiro, RJ, Brasil $17^{\circ}$ Ergodesign - Congresso Internacional de Ergonomia e Usabilidade de Interfaces Humano Tecnológica: Produto, Informações Ambientes Construídos e Transporte

$17^{\circ}$ USIHC - Congresso Internacional de Ergonomia e Usabilidade de Interfaces Humano Computador

Figura 19 - Resultados do Teste de Erick aplicados com o protótipo

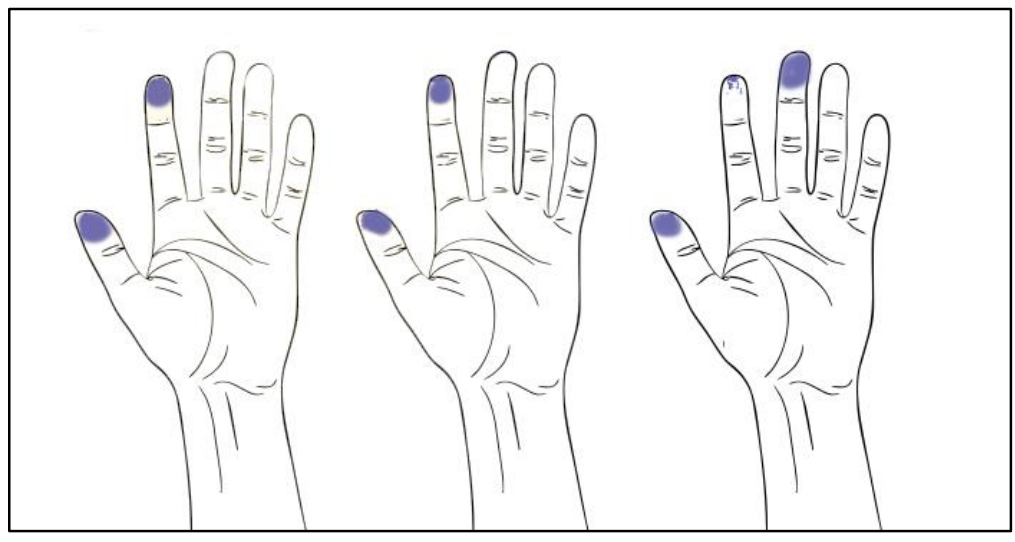

Fonte: Os autores

\section{CONSIDERAÇÕES FINAIS}

Protetores de tomada são acessórios de extrema importância para diminuir riscos de acidentes elétricos no ambiente doméstico. Entretanto, verificou-se na pesquisa que eles são pouco utilizados por não atenderem às necessidades do usuário de forma eficiente. A partir das entrevistas, notou-se que ainda se faz o uso de alternativas como o uso de fitas adesivas, o reposicionamento de móveis para servir de obstáculo e até mesmo isolar ambientes inteiros, como quartos que possuem tomadas elétricas posicionadas abaixo de 1 metro de altura, para afastar crianças pequenas desses canais de corrente elétrica.

O projeto buscou abordar este problema a partir do desenvolvimento de um novo produto, que garantisse ao usuário maior conforto e segurança, devido a um sistema semiautomático para isolar os orifícios da tomada, diminuindo as fases da realização da tarefa, além disso possui maior área de contato para garantir uma remoção mais fácil do acessório, por adultos, quando necessária. $\mathrm{O}$ acesso e consulta às tabelas antropométricas, de biomecânica e a norma NBR 14136, foram de grande valia para pensar-se os aspectos de dimensionamento e manejo do produto.

A estratégia para dificultar a retirada do acessório por crianças foi projetar a área de pega nas extremidades laterais do produto, sabendo que a abertura funcional da criança é menor que as medidas do comprimento total do protetor de tomada proposto, além de uma superfície colante para melhor fixação, visando minimizar os riscos de remoções acidentais. Os testes realizados mostram que houve a melhora dos problemas identificados e o aumento da satisfação dos usuários devido a melhor experiência de uso. Em geral, o projeto apresenta uma alternativa satisfatória para o desenvolvimento de novos modelos de protetores de tomadas.

Apesar dos resultados iniciais obtidos, é necessário verificar alguns ajustes como as dimensões dos orifícios do protetor de tomada, espessuras da placa interna, a melhor definição do sistema semiautomático, além da identificação do melhor material e capacidade de fixação da superfície colante, para então assim, prosseguir para as posteriores fases de produção.

Sobretudo destaca-se a importante integração entre as disciplinas de Projeto de Produto e 
Ergonomia, as quais aliadas à tecnologia de impressão 3D permitiram aos discentes a experiência do desenvolvimento de projeto para um problema real, desde a análise do problema até a validação da alternativa desenvolvida.

\section{REFERÊNCIAS}

ABNT. NBR 14136: Plugues e tomadas para uso doméstico e análogo até $20 \mathrm{~A} / 250 \mathrm{~V}$ em corrente alternada - Padronização. 2 ed. Rio de Janeiro: Associação Brasileira de Normas Técnicas, 2012.

ABNT. NR 10: Segurança em instalações e serviços em eletricidade. Rio de Janeiro: Associação Brasileira de Normas Técnicas, 2004.

ABRACOPEL. Anuário Estatístico Abrocopel: Acidentes de Origem Elétrica 2019 (ano base 2018). 2019. Disponível em: <http://abracopel.org/wp-content/uploads/2019/05/Anu\%C3\% A1rio-ABRACOPEL-2019.pdf>. Acesso em: 21 de abril de 2019.

BAXTER, Mike. Projeto de Produto: Guia prático para o design de novos produtos. 2. ed. São Paulo: Editora Blucher, 2005.

BAXTER, Mike. Projeto de Produto: Guia prático para o design de novos produtos. 3. ed. São Paulo: Editora Blucher, 2011.

BEZERRA, Maria Augusta Rocha, et al. Acidentes domésticos em crianças: concepções práticas dos agentes comunitários de saúde. Cogitare Enferm. 2014 Out/Dez; 19(4):776-84.

BOMFIM, Gustavo Amarante. Metodologia para Desenvolvimento de Projetos. João Pessoa: Editora Universitária/UFPB, 1995.

BRANDÃO, Eduardo Rangel. Sistematização do Homem-Tarefa-Máquina (SHTM), 2012. Disponível em: https://pt.slideshare.net/eduardobrandao/sistematizao-do-sistemahomemtarefamquina-shtm. Acesso em 19 de abril de 2017.

BROOKE, John. SUS - A quick and dirty usability scale. 1986. Disponível em: http://dag.idi.ntnu.no/IT3402_2009/sus_background.pdf. Acesso em 20 de abril de 2017.

BUZAN, Tony. Mapas mentais e sua elaboração: um sistema definitivo de pensamento que transformará a sua vida. São Paulo: Cultrix, 2005.

CAVALCANTI, Janaina Ferreira. Análise ergonômica da sinalização de segurança: Um enfoque da ergonomia informacional e cultural. 229 f. Dissertação (Mestrado) - Curso de Engenharia de Produção, Universidade Federal de Pernambuco, Recife, 2003.

CUNHA, Karenine; MANTELLO, Paulo. 2014. Era uma Vez a Notícia: Storytelling como Técnica de Redação de Textos Jornalísticos. Comunicação Midiática, v. 9, n. 2, 2014.

LOBACH, Bernd. Design Industrial: Base para a configuração dos produtos industriais. Editora Blucher. São Paulo, 2000.

MALACARNE, J. Mortes de crianças por acidentes com eletricidade aumentam mais de 50\% no brasil. Crescer, 2016. Disponível em 
<https://revistacrescer.globo.com/Criancas/Seguranca/noticia/2016/03/mortes-de-criancas-poracidentes-com-eletricidade-aumentam-mais-de-50-no-brasil.html> Acesso em 10 de setembro de 2019.

MCDONAGH, D., \& DENTON, H. Exploring the degree to which individual students share a common perception of specific mood boards: Observations relating to teaching, learning and team-based design. Design Studies, 2005.

MORAES, Anamaria de; MONT'ALVÃO, Cláudia. Ergonomia: Conceitos e aplicações. 2. ed. Rio de Janeiro: 2ab, 2000.

PASCHOARELLI, Luis Carlos. Aspectos Ergonômicos e de Usabilidade no Design de Pegas e Empunhaduras. Estudos em Design. vol. 8. Rio de Janeiro: Abril, 2000.

PHEASANT, S. Bodyspace - Anthropometry, Ergonomics and Design of Work. Taylor \& Francis, 1996.

SANDERS, M.S.; McCORMICK, E. J. Human Error, Accidents, and Safety. In: SANDERS, M.S.; McCORMICK, E. J. Human Factors in Engineering and Design. 7 th ed. New York: McGraw-Hill, 1993. chap. 20, p. 655 - 695.

SANTOS, M. A. da S. Choque elétrico, um verdadeiro perigo. Mundo Educação. Disponível em: < http://mundoeducacao.bol.uol.com.br/fisica/choque-eletrico-um-verdadeiro-perigo.htm> Acesso em 10 de setembro de 2019.

VIANNA, Y.; VIANNA, M.; ADLER, I. K. Design thinking: inovação em negócios. Rio de Janeiro: MJV Press, 2012. 